\title{
Implications of intra-seasonal climate variations on chlorophyll $a$ fluorescence and biomass in winter barley breeding program
}

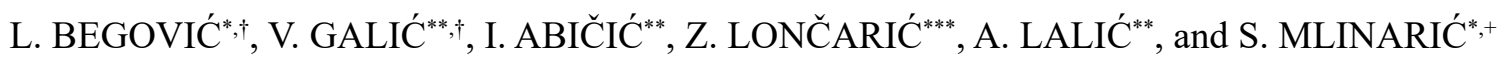 \\ Department of Biology, Josip Juraj Strossmayer University of Osijek, Cara Hadrijana 8/A, HR-31000 Osijek, \\ Croatia* $^{*}$ \\ Agricultural Institute Osijek, Južno predgrađe 17, HR-31000 Osijek, Croatia** \\ Faculty of Agrobiotechnical Sciences Osijek, Josip Juraj Strossmayer University of Osijek, Vladimira Preloga 1, \\ HR-31000 Osijek, Croatia ${ }^{* * *}$
}

\begin{abstract}
This study aimed to explore how ten selected winter barley genotypes responded to variations in environmental conditions during the growth season by using fast chlorophyll $a$ fluorescence and normalized difference vegetation index (NDVI) at the booting, anthesis and early grain-filling stage. Lower amount of rainfall during the anthesis induced instability in the function of PSII, observed as the positive K-band in six and the positive L-band in seven genotypes. At grain filling, all genotypes displayed negative K- and L-bands, suggesting an increase of stability within PSII. The performance index increased from booting to grain filling in most genotypes. Chlorophyll $a$ fluorescence parameters were incorporated into the partial least squares model as explanatory variables of NDVI. After a cross-validation, the model with four latent variables was chosen explaining $75.8 \%$ variance $(r=0.870)$ for NDVI. The principal component analyses showed two distinct types of the reaction of the barley genotypes to the mild drought stress at anthesis.
\end{abstract}

Additional key words: abiotic stress; carbon; Hordeum vulgare L.; nitrogen.

\section{Introduction}

One of the major challenges in the global agricultural production is creating crops tolerant to stresses that affect plant productivity in cropping systems. Such decrease of crop productivity has challenged food security (Hanjra and Qureshi 2010). Plant responses to stress are complex and they are influenced by both environmental and genetic factors (Reynolds et al. 2016). Climate variations affect a plant performance and are able to modify a phenotype expression on the morphological and physiological levels (Cassman et al. 2011). Limiting environmental factors, such as drought, heat stress, salt stress, and flooding, affect plant performance. One of the most important factors affecting plant growth and development is drought which induces different physiological and molecular responses, such as a decreased photosynthetic performance and changes in different biochemical pathways, on transcriptome, metabolome, and proteome levels (Ahuja et al. 2010).

In crops, changes in temperature and daily rainfall affect both crop yield and nutritional quality (Porter and Semenov 2005). Studies of the interaction between different barley genotypes (cultivars) and environments give useful information about yield stability and quality

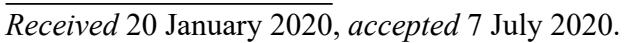

${ }^{+}$Corresponding author; e-mail: smlinaric@biologija.unios.hr

Abbreviations: ABS - absorption flux; $\mathrm{ABS} / \mathrm{RC}$ - absorption flux per active RC; ChlF - chlorophyll $a$ fluorescence; $\mathrm{DF}_{\mathrm{ABS}}-$ total driving force; $\mathrm{DI}_{0} / \mathrm{RC}$ - dissipation flux per active $\mathrm{RC} ; \mathrm{DM}$ - dry mass; $\mathrm{ET}_{0} / \mathrm{RC}$ - electron transport flux per active $\mathrm{RC} ; \mathrm{F}_{0}-$ minimal fluorescence intensity; $F_{300}$ - fluorescence intensity at $300 \mu \mathrm{s} ; \mathrm{F}_{\mathrm{I}}$ - fluorescence intensity at $2 \mathrm{~ms} ; \mathrm{F}_{\mathrm{J}}$ - fluorescence intensity at $30 \mathrm{~ms} ; \mathrm{F}_{\mathrm{m}}-\mathrm{maximal}$ fluorescence intensity; $\mathrm{F}_{\mathrm{V}}$ - maximal variable fluorescence; LSD - Fisher's Least Significant Difference test; $\mathrm{M}_{0}$ - approximated initial slope of relative variable fluorescence $\mathrm{F}_{\mathrm{v}}$; NDVI - normalized difference vegetation index; PC - principal component; PCA - principal component analysis; $\mathrm{PI}_{\mathrm{ABS}}$ - performance index on absorption basis; PLS - partial least squares (regression); RC - reaction center; $\mathrm{RCBD}$ - randomized complete block design; RC/ABS - density of RC on chlorophyll $a$ basis; $\mathrm{RC} / \mathrm{CS}_{0}$ - density of active RC per excited cross section; $\mathrm{RE}_{0} / \mathrm{RC}$ - electron flux reducing end electron acceptors at the PSI acceptor side, per $\mathrm{RC} ; \mathrm{t}_{\mathrm{Fm}}-$ time needed to reach $\mathrm{F}_{\mathrm{m}}$; $\mathrm{TR}_{0} / \mathrm{RC}$ - trapping flux per active $\mathrm{RC} ; \mathrm{V}_{\mathrm{I}}$ - relative variable fluorescence at $30 \mathrm{~ms}$ (I step); $\mathrm{V}_{\mathrm{J}}$ - relative variable fluorescence at $2 \mathrm{~ms}$ $(\mathrm{J}$ step $) ; \mathrm{V}_{\mathrm{K}}$ - relative variable fluorescence at $300 \mu \mathrm{s}(\mathrm{K}$ step $) ; \mathrm{V}_{\mathrm{L}}$ - relative variable fluorescence at $150 \mu \mathrm{s}\left(\mathrm{L}\right.$ step); $\mathrm{V}_{\mathrm{t}}-$ relative variable fluorescence at time $t ; \Delta \mathrm{DF}_{\mathrm{ABS}}$ - relative changes in the difference of driving forces; $\Delta \mathrm{V}_{\mathrm{OJ}}-$ difference kinetics between $\mathrm{O}$ and $\mathrm{J}$ steps; $\Delta \mathrm{V}_{\mathrm{OK}}$ - difference kinetics between $\mathrm{O}$ and $\mathrm{K}$ steps; $\delta_{\mathrm{R} 0}$ - efficiency/probability with which an electron from the intersystem electron carriers moves to reduce end electron acceptors at the PSI acceptor side; $\varphi_{\mathrm{E} 0}$ - probability that absorbed photon moves an electron further than $\mathrm{Q}_{\mathrm{A}}^{-} ; \varphi_{\mathrm{P} 0}$ - maximum quantum yield of PSII; $\varphi_{\mathrm{R} 0}$ - probability that absorbed photon moves an electron further than $\mathrm{Q}_{\mathrm{A}}^{-} ; \rho_{\mathrm{Red}}-$ red radiation; $\psi_{\mathrm{E} 0}-$ probability that trapped exciton moves an electron further than $\mathrm{Q}_{\mathrm{A}}^{-}$.

Acknowledgements: This work was funded by Adris Foundation (Croatia) under 'The Knowledge and Discovery' Program.

†L. Begović and V. Galić contributed equally to this work. 
(Lalić et al. 2010). The insight into complex networks of molecular interactions controlling plant acclimation to field conditions could significantly improve chances for developing crops with an enhanced tolerance to field conditions. This imposes a need for breeding and selection of the genotypes with better adaptation to diverse climate regimes.

Within recent years, one of the emerging noninvasive methods often used for assessment of canopy greenness is normalized difference vegetative index - NDVI (Raun et al. 2001). NDVI is an index derived from spectral reflectance peaks and represents one of many spectral vegetation indices in use ( $\mathrm{Li}$ et al. 2014). Use of NDVI and other vegetation indices derived from measurements of canopy reflectance has been demonstrated in the evaluation of green biomass (Cabrera-Bosquet et al. 2011) and the in-season estimation of a grain yield in crops such as wheat (Walsh et al. 2013). In crop breeding, there is a growing demand for new, high-throughput phenotyping methods that are reliable and can integrate measurements over time and space and offer information about the efficiency of the use of resources (Araus and Cairns 2014) such as fertilizers and crop adaptations to unfavourable environmental conditions (Reynolds and Langridge 2016). Plant carbon and nitrogen contents as well as their ratio $(\mathrm{C} / \mathrm{N})$ have a significant impact on a crop yield and grain quality (Lawlor 2002). The $\mathrm{C} / \mathrm{N}$ ratio presents a valuable indicator for diagnosing the balance of carbon and nitrogen, growth, and nutrient status in crop plants (Xu et al. 2015), and it is usually estimated by invasive chemical methods.

Chlorophyll (Chl) $a$ fluorescence is another responsive, noninvasive method for measuring plant performance by assessment of photosynthetic efficiency in different environmental conditions (Oukarroum et al. 2007, Kalaji et al. 2012, Brestič et al. 2018). Chl a kinetics can be used to describe energy transfer within PSII (Strasser et al. 2004). Parameters obtained by the JIP-test are used for determination of the relationship between a structure (chemical inventory and architecture of pigment assemblies) and a function of photosynthetic apparatus (Strauss et al. 2006). They also describe the connection between $\mathrm{Chl}$ fluorescence and biological functions (Strasser et al. 2004) through the biophysical interpretation of parameters derived from measured transients. Abiotic stresses, such as drought, salt, and light stress, can have a direct or an indirect impact on the photosynthetic activity and modify the Chl $a$ fluorescence kinetics (Živčák et al. 2008, Kalaji et al. 2011, Sun et al. 2016, Kalaji et al. 2018). Chl $a$ fluorescence is broadly used for screening of responses of different plant species and/or genotypes to stress and can be a useful method for the screening of stress-tolerant and -sensitive genotypes in different crop species (Prasad et al. 2008). As it represents a data-rich, high throughput approach readily used as a selection criterion (Kalaji and Guo 2008), it conforms to the needs of breeders in selection processes (Araus and Cairns 2014).

Barley is one of the first cereals cultivated and adapted for cultivation (Badr et al. 2000). It occupies the fourth place in cereal production in the world and the third one in Europe according to Eurostat. One of its most significant characteristics is the ability to adapt to various climatic conditions making it suitable for growing from subarctic to subtropical areas. It is most often grown in moderate climate areas. More than a thousand cultivars, which meet market and industry requirements, have been produced so far through the processes of breeding and selection. There are also different winter and spring cultivars phenotypically adapted to different climatic conditions. Most of barley is grown for cattle feeding ( $85 \%$ of total production) and the rest is used for malting in the brewing industry and the production of other drinks and food supplements according to FAOSTAT. Historically, barley was more represented in human nutrition, before the intensification of wheat and rice production. Today, it is still prevalent in the countries (Africa, Asia) with unfavourable climate conditions for wheat cultivation, although it is becoming more and more popular in developed parts of the world.

The main objective of this study was to screen and evaluate the adaptation of ten winter barley cultivars, from the late stage of a barley breeding program, to the intraseason variations of climate during the growth in the experimental fields where they were exposed to randomly stressful conditions. Namely, influences of these changes on the functioning of the photosynthetic apparatus and biomass traits were in focus of this study. In addition, this study aimed to explore the possibility of using chlorophyll $a$ fluorescence for screening of barley genotypes in terms of predicting stress-tolerant and -sensitive cultivars. It can considerably contribute to the future selection and the breeding process.

\section{Materials and methods}

Plant material and field trial: Ten winter barley cultivars, from a larger set of late stage Agricultural Institute Osijek (AIO) breeding program, were selected for this research. Plant material contrasted in several agronomic traits, such as grain yield, maturity date, and spike configuration (Table 1S, supplement).

The five-day difference in ripening was considered as maturity group switching criterion. Field trial was set as a randomized complete block (RCBD) with three replicates during 2017/2018 growing season at Agricultural Institute Osijek $\left(45^{\circ} 32^{\prime} \mathrm{N}, 18^{\circ} 44^{\prime} \mathrm{E}\right)$. Plants were grown under natural rain-fed conditions. Crops were sown during fall (9 October 2017) with 450 grains $\mathrm{m}^{-2}$ on $7.56 \mathrm{~m}^{2}$ plots. Grain yield was estimated for every separately harvested replicate on trial basis $\left(7.56 \mathrm{~m}^{2}\right.$ plot $)$ which was considered as a technical replicate. Soil type at the growing site is eutric cambisol with $\mathrm{pH}$ 6.5. Nonlimiting contents of nutrients were applied prior to sowing with $50 \mathrm{~kg} \mathrm{ha}^{-1}$ of urea $(46 \%$ of $\mathrm{N})$, with subsequent application of $400 \mathrm{~kg}$ $\mathrm{ha}^{-1}$ of NPK fertilizer (formulation 7:20:30) as a starter and with additional fertilizing just before awn emergence stage with $70 \mathrm{~kg} \mathrm{ha}^{-1}$ of KAN ( $27 \%$ of $\left.\mathrm{N}\right)$. Weeds and diseases were controlled as necessary. Weather data, including rainfall and temperature were obtained from the Agricultural Institute Osijek measuring station, which was located less than a kilometre from the experimental site. Total rainfall during the growing season (October 2017 till 
June 2018) was $426.8 \mathrm{~mm}$ with 23.3 mean maximum and $10.5^{\circ} \mathrm{C}$ mean minimum temperature. Between booting and anthesis recorded precipitation was $0.8 \mathrm{~mm}$, while between anthesis and grain-filling stage precipitation was $0.6 \mathrm{~mm}$ in total. The mean temperatures and rainfall between the stages booting, anthesis, and grain filling are presented in Fig. 1S (supplement).

Normalized difference vegetation index (NDVI) and agronomical traits: Measurements were performed using Trimble GreenSeeker ${ }^{\circledR}$ crop sensing system (Trimble, USA). NDVI was measured at booting, anthesis, and grain-filling stage across the whole section of the trial. Moving at a constant speed along the rows between plots, the GreenSeeker was held at about $60 \mathrm{~cm}$ above the crop canopy and its effective resolution captured approximately four inner rows out of 14 in a single plot. At ripening stage, in June 2018, the whole plot was harvested for determination of grain yield using a plot harvester. Yield was expressed in $\mathrm{t} \mathrm{ha}^{-1}$ at $14 \%$ of grain moisture.

Carbon $(C)$ and nitrogen $(N)$ content: The $C: N$ ratio in plant tissue was analysed after determination of total organic $\mathrm{C}$ and total $\mathrm{N}$ concentrations in dry plant samples. Total organic carbon concentration in plant samples was determined by sulfochromic oxidation (mixture of potassium dichromate solution and sulphuric acid at a temperature of $135^{\circ} \mathrm{C}$ ) and colour intensity was measured spectrophotometrically (Cary 50 Conc, Varian, CA, USA) (Manojlović et al. 2019). The method was calibrated using glucose solution. The sample size in organic $\mathrm{C}$ analyses was $50 \mathrm{mg}$ and therefore six repetitions for each sample were done. $\mathrm{N}$ content in plant samples was determined by the Kjeldahl method (Behr Distillation Unit

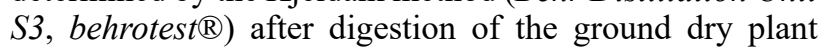
material with sulphuric acid (Digest block system K-437, Buchi Corporation, NC, USA). The sample size in total N analysis was $500 \mathrm{mg}$ and three repetitions for each sample were analysed.

Fast Chl $\boldsymbol{a}$ fluorescence measurement: Fast Chl $a$ fluorescence (ChlF) transients were measured with Handy PEA (Hansatech Instruments Ltd., Norfolk, UK) on flag leaves of ten barley cultivars. All measurements were performed in the field on the leaves that were dark-adapted for $30 \mathrm{~min}$ with leaf clips. Data obtained at the booting stage served as control. ChlF transients were induced with a pulse of saturating red light $\left[3,200 \mu \mathrm{mol}\right.$ (photon) $\mathrm{m}^{-2} \mathrm{~s}^{-1}$, $\lambda=650 \mathrm{~nm}]$. The OJIP kinetics of transients was measured by recording data from $20 \mu \mathrm{s}$ to $1 \mathrm{~s}$ with resolution of 118 data points. Recorded fluorescence transients were analysed using the JIP-test (Strasser et al. 2000, 2004). Calculations and biophysical descriptions of used parameters are shown in Table $2 \mathrm{~S}$ (supplement). Total driving force $\left(\mathrm{DF}_{\mathrm{ABS}}\right)$ for photosynthesis of the observed system, presented as $\log \mathrm{PI}_{\mathrm{ABS}}$, is summed up by the corresponding partial driving forces: $\log \gamma_{\mathrm{RC}} /\left(1-\gamma_{\mathrm{RC}}\right), \log \varphi_{\mathrm{P} 0} /\left(1-\varphi_{\mathrm{P} 0}\right)$, and $\log \psi_{\mathrm{E} 0} /\left(1-\psi_{\mathrm{E} 0}\right)$. The difference for the booting and the anthesis and/or grain-filling stage, respectively, $\Delta \mathrm{DF}_{\mathrm{ABS}}$ was calculated as $\Delta \mathrm{DF}=\mathrm{DF}_{\text {anthesis/grain filling }}-\mathrm{DF}_{\text {booting. }}$ To compare recorded OJIP transients for specific events in the $\mathrm{OJ}$ and $\mathrm{OK}$ phases, the difference in the relative variable fluorescence was calculated and presented as $\Delta \mathrm{V}_{\mathrm{OJ}}$ and $\Delta \mathrm{V}_{\mathrm{OK}}$ normalized to the booting developmental stage (Yusuf et al. 2010). In every $7.56 \mathrm{~m}^{2}$ plot (biological replicate), 15 plants were measured (field technical replicates). In the data processing stage and outlier removal, 40 of 45 measurements for each genotype were kept, comprising totally 800 technical replicates (plants) left for JIP-test analyses on ten cultivars basis.

Principal component analysis: Briefly, principal component analysis (PCA) aims to best represent the variation in the data based on a multitude of original variables. This is achieved by finding the latent variables principal components made from linear combinations of original data that will most efficiently capture the variation in the original dataset. PCs represent statistical models with the scores (distance from the PC origin for every data point), the loadings (variable contributions for each PC), and the residuals (Bro and Smilde 2014). PCA efficiently solves the collinearity between variables (Wold et al. 1987), and was hence used to analyse the ChlF data. Parameters $t_{\mathrm{Fm}}$, $\mathrm{V}_{\mathrm{J}}, \mathrm{ABS} / \mathrm{RC}, \mathrm{DI}_{0} / \mathrm{RC}, \mathrm{TR}_{0} / \mathrm{RC}, \mathrm{ET}_{0} / \mathrm{RC}, \mathrm{RE}_{0} / \mathrm{RC}, \varphi_{\mathrm{P} 0}, \varphi_{\mathrm{E} 0}$, $\mathrm{RC} / \mathrm{CS}_{0}, \mathrm{PI}_{\mathrm{ABS}}$, NDVI, and grain yield were used as input to set a PCA model. All the variables were scaled, centred, and $\log$ transformed. The components explaining at least $10 \%$ of variation present in the dataset were analysed. The analysis was performed in $R$ environment ( $R$ Development Core Team 2019) with $R$ 's own function prcomp. Plots were constructed using the R/ggbiplot package ( Vu 2011).

Proline and dry mass content: For proline and dry mass (DM) analyses, 20-30 plants were sampled from each plot in three growth stages (booting, anthesis, and grain filling). Flag leaves were combined for each genotype separately and from this combined sample, three technical replicates were analysed. The tissue was ground in liquid nitrogen using mortar and pestle. For determination of proline, tissue was dried at $65^{\circ} \mathrm{C}$ for $48 \mathrm{~h}$ and for dry mass content, tissue was dried at $105^{\circ} \mathrm{C}$ for $24 \mathrm{~h}$. Proline content was determined according to Carillo and Gibon (2011). Dried tissue $(20 \mathrm{mg})$ was extracted overnight at $4^{\circ} \mathrm{C}$ with $400 \mu \mathrm{L}$ in ethanol:water (40:60, v/v). After centrifugation, $50 \mu \mathrm{L}$ of ethanol extract was used for measuring proline content on microplate reader (Tecan Spark, Männedorf, Switzerland) at $520 \mathrm{~nm}$. Proline content in ten barley cultivars was calculated from the standard curve using proline as standard and expressed as nmol per mg of dry mass (DM).

Statistical analyses: Statistical differences between selected winter barley cultivars were analysed using the factorial analysis of variance (ANOVA) followed by posthoc Fisher's Least Significant Difference test (LSD). Differences were considered significant at $p<0.05$. For fluorescence measurements, each data point represents the mean \pm standard deviation of 40 independently measured plants, e.g., technical replicates on plot basis $(n=40)$ and all data were normalized to the booting stage to adequately 
compare different cultivars. The linear model between the logarithm of electron transport quantum yield $\left(\varphi_{\mathrm{E} 0}\right.$, $\mathrm{ET}_{0} / \mathrm{ABS}$ ) relative to performance in booting, and logarithm of $\mathrm{PI}_{\mathrm{ABS}}$ relative to performance in booting was set in $R$ with 40 independently measured plant values per barley variety normalized to the performance in booting $(n=800)$. Chl fluorescence and reflectance indices such as NDVI are known to be sensitive methods for evaluation of stress occurrence in plants (Lichtenthaler et al. 1998). Compared to Chl fluorescence, NDVI measures the fraction of photosynthetic radiation absorbed by plants, without assessment of the utilization efficacy on the plant side (Cavender-Bares and Bazzaz 2004). In order to test informativeness of NDVI in faster assessment of general photosynthetic performance of varieties, a partial least squares (PLS) model was set. PLS model with NDVI as dependent variable (y), and all 56 calculated biophysical ChlF parameters used for PCA (Strasser et al. 2010) as predictors (x) was set in R/pls library (Mevik et al. 2018). Model was calibrated with 10 -fold cross-validation procedure. Agronomic parameters were analysed in $R$ by the means of $A N O V A$, and the post-hoc tests were applied after the inspection of the residuals for normality using packages car and agricolae.

\section{Results}

NDVI, yield variability, and proline content: Maximum NDVI values among all barley cultivars were observed at the booting stage. Cultivars Osk.5.36/25-15, Pleter, and Zlatko showed the highest values of NDVI in booting (Table 1) and the similar results were also observed in the anthesis. At the anthesis stage, the cultivar Titan showed the lowest and cultivars Osk.5.36/25-15 the highest NDVI value. At the grain-filling stage, a large overall drop in values occurred in all investigated cultivars. Notably, the lowest value was recorded in the cultivar Titan, belonging to the early group of cultivars.

Grain yield of ten winter barley cultivars is shown in Table 1. The cultivar Osvit had significantly a lower grain yield. The cultivar Predator showed the highest grain yield of $8.063 \mathrm{t} \mathrm{ha}^{-1}$. Genotypic effects on barley grain yield were less pronounced with regard to data acquisition in a single year of the field trials.

The increase in proline content at anthesis, followed by a decline at grain filling was observed in all genotypes except for Barun. The significantly highest mean values of proline and dry mass were observed at anthesis. No significant differences were observed for dry mass content between the anthesis and grain-filling stage (Table 2).

Changes in OJIP transients in selected winter barley cultivars: The apparent difference in the L- and K-band (Fig. 1) was observed at anthesis and grain filling. While at anthesis only three genotypes - Barun, Osk.5.36/25-15, and Lord - revealed negative amplitudes of L-band (Fig. $1 A)$, at grain filling, all ten selected genotypes showed negative amplitudes (Fig. $1 B$ ). The K-band at anthesis (Fig. $1 C)$ revealed completely negative amplitudes in Predator, Barun, Osk.5.36/25-15, and Lord genotypes. Genotypes Zlatko, Bravo, Pleter, and Maestro showed negative inflections, while Titan and Osvit showed mainly positive amplitudes. At grain filling (Fig. 1D), completely negative K-band amplitudes were observed in all ten genotypes.

To evaluate the condition of the photosynthetic apparatus in ten winter barley genotypes, selected structural and functional parameters calculated from JIP-test were chosen: $\mathrm{PI}_{\mathrm{ABS}}, \varphi_{\mathrm{P} 0}, \psi_{\mathrm{E} 0}, \varphi_{\mathrm{E} 0}, \delta_{\mathrm{R} 0}, \varphi_{\mathrm{R} 0}, \mathrm{RC} / \mathrm{CS}_{0}, \mathrm{ABS} / \mathrm{RC}$, $\mathrm{DI}_{0} / \mathrm{RC}, \mathrm{TR}_{0} / \mathrm{RC}, \mathrm{ET}_{0} / \mathrm{RC}, \mathrm{RE}_{0} / \mathrm{RC}, \mathrm{t}_{\mathrm{Fm}}, \mathrm{V}_{\mathrm{I}}$, and $\mathrm{V}_{\mathrm{J}}$ (Fig. 2). Each genotype was normalized to its respective control measured at booting. Genotypes Osvit and Lord (Fig. 2A,J; Table 3S, supplement) exhibited significant changes in multiple parameters at anthesis, while Titan and Osk.5.36/25-15 at both, anthesis and grain-filling stage (Fig. 2D,I; Table 3S).

The measure of multiparametric driving force (DF) of total photosynthetic electron transport is created by summing up the partial driving forces (Fig. 3) of $\mathrm{PI}_{\mathrm{ABS}}$. At anthesis, the highest increase of $\triangle \mathrm{DF}_{\mathrm{ABS}}$ can be seen in genotypes Lord and Osk.5.36/25-15 (Fig. 3A). In both cultivars, the increase of the difference in all three parameters contributed equally to the overall increase of $\triangle \mathrm{DF}_{\mathrm{ABS}}$ at anthesis. Zlatko and Titan were the only two genotypes showing negative $\Delta \mathrm{DF}_{\mathrm{ABS}}$ at anthesis. At grain

Table 1. Analysis of variance for grain yield and normalized difference vegetation index (NDVI) at three growth stages: booting, anthesis, and grain filling of ten barley cultivars. Different letters in superscript represent statistical significance at $p \leq 0.05$. Data are the means of three biological replicates \pm standard error of mean $(n=3)$.

\begin{tabular}{lllll}
\hline Cultivar & Grain yield $\left[\mathrm{t} \mathrm{ha}{ }^{-1}\right]$ & NDVI (booting) & NDVI (anthesis) & NDVI (grain filling) \\
\hline Pleter & $7.753 \pm 0.80^{\mathrm{ab}}$ & $0.813 \pm 0.015^{\mathrm{a}}$ & $0.747 \pm 0.021^{\mathrm{ab}}$ & $0.280 \pm 0.046^{\mathrm{bc}}$ \\
Zlatko & $7.917 \pm 0.65^{\mathrm{ab}}$ & $0.813 \pm 0.015^{\mathrm{bc}}$ & $0.743 \pm 0.021^{\mathrm{ab}}$ & $0.263 \pm 0.010^{\mathrm{bc}}$ \\
Titan & $6.860 \pm 0.28^{\mathrm{cd}}$ & $0.767 \pm 0.021^{\mathrm{bc}}$ & $0.703 \pm 0.021^{\mathrm{c}}$ & $0.193 \pm 0.035^{\mathrm{c}}$ \\
Osvit & $5.377 \pm 0.36^{\mathrm{d}}$ & $0.780 \pm 0.027^{\mathrm{bc}}$ & $0.710 \pm 0.027^{\mathrm{bc}}$ & $0.250 \pm 0.030^{\mathrm{c}}$ \\
Barun & $7.100 \pm 1.33^{\mathrm{bc}}$ & $0.800 \pm 0.017^{\mathrm{bc}}$ & $0.727 \pm 0.015^{\mathrm{bc}}$ & $0.287 \pm 0.072^{\mathrm{c}}$ \\
Predator & $8.063 \pm 1.41^{\mathrm{a}}$ & $0.770 \pm 0.020^{\mathrm{c}}$ & $0.710 \pm 0.035^{\mathrm{c}}$ & $0.303 \pm 0.025^{\mathrm{c}}$ \\
Bravo & $7.330 \pm 0.39^{\mathrm{bc}}$ & $0.807 \pm 0.011^{\mathrm{abc}}$ & $0.747 \pm 0.029^{\mathrm{ab}}$ & $0.367 \pm 0.040^{\mathrm{bc}}$ \\
Maestro & $6.897 \pm 1.83^{\mathrm{ab}}$ & $0.797 \pm 0.015^{\mathrm{ab}}$ & $0.743 \pm 0.038^{\mathrm{bc}}$ & $0.323 \pm 0.055^{\mathrm{bc}}$ \\
Lord & $7.280 \pm 0.85^{\mathrm{bc}}$ & $0.797 \pm 0.035^{\mathrm{ab}}$ & $0.777 \pm 0.035^{\mathrm{bc}}$ & $0.400 \pm 0.035^{\mathrm{ab}}$ \\
Osk.5.36/25-15 & $7.410 \pm 1.12^{\mathrm{bc}}$ & $0.840 \pm 0.020^{\mathrm{bc}}$ & $0.797 \pm 0.035^{\mathrm{a}}$ & $0.490 \pm 0.040^{\mathrm{a}}$ \\
\hline
\end{tabular}


Table 2. Proline content $\left[\mathrm{nmol} \mathrm{mg}^{-1}(\mathrm{DM})\right]$ and dry mass content $(\mathrm{DM})$ in leaves of ten barley genotypes measured in three developmental stages: booting, anthesis, and grain filling along with standard deviations $(n=3)$. Different letters in superscript represent significance between means of all cultivars at different developmental stages at $p \leq 0.05$.

\begin{tabular}{|c|c|c|c|c|c|c|}
\hline \multirow{2}{*}{$\begin{array}{l}\text { Stage } \\
\text { Cultivar }\end{array}$} & \multicolumn{2}{|l|}{ Booting } & \multicolumn{2}{|l|}{ Anthesis } & \multicolumn{2}{|l|}{ Grain filling } \\
\hline & Proline & DM & Proline & DM & Proline & DM \\
\hline Pleter & $0.049 \pm 0.001^{\mathrm{d}}$ & $0.202 \pm 0.019^{\mathrm{bc}}$ & $0.095 \pm 0.007^{\mathrm{b}}$ & $0.277 \pm 0.020^{\mathrm{bc}}$ & $0.085 \pm 0.004^{\mathrm{a}}$ & $0.296 \pm 0.031^{\mathrm{abc}}$ \\
\hline Zlatko & $0.078 \pm 0.003^{\mathrm{a}}$ & $0.240 \pm 0.022^{\mathrm{a}}$ & $0.090 \pm 0.007^{\mathrm{bc}}$ & $0.276 \pm 0.025^{\mathrm{bc}}$ & $0.068 \pm 0.003^{\mathrm{de}}$ & $0.266 \pm 0.017^{\mathrm{bcd}}$ \\
\hline Titan & $0.070 \pm 0.005^{\mathrm{b}}$ & $0.245 \pm 0.031^{\mathrm{a}}$ & $0.087 \pm 0.006^{\mathrm{bc}}$ & $0.281 \pm 0.083^{\mathrm{bc}}$ & $0.054 \pm 0.003^{g}$ & $0.285 \pm 0.042^{\mathrm{abcd}}$ \\
\hline Osvit & $0.059 \pm 0.001^{\mathrm{c}}$ & $0.241 \pm 0.013^{\mathrm{a}}$ & $0.087 \pm 0.007^{\mathrm{bc}}$ & $0.270 \pm 0.040^{c}$ & $0.079 \pm 0.002^{\mathrm{ab}}$ & $0.292 \pm 0.037^{\mathrm{abcd}}$ \\
\hline Barun & $0.064 \pm 0.009^{\mathrm{bc}}$ & $0.183 \pm 0.008^{\mathrm{cd}}$ & $0.061 \pm 0.004^{\mathrm{e}}$ & $0.451 \pm 0.139^{\mathrm{a}}$ & $0.060 \pm 0.001^{\mathrm{fg}}$ & $0.333 \pm 0.024^{\mathrm{a}}$ \\
\hline Predator & $0.063 \pm 0.002^{\mathrm{bc}}$ & $0.239 \pm 0.016^{\mathrm{a}}$ & $0.076 \pm 0.005^{\mathrm{d}}$ & $0.264 \pm 0.063^{\mathrm{c}}$ & $0.071 \pm 0.005^{\mathrm{cd}}$ & $0.323 \pm 0.020^{\mathrm{ab}}$ \\
\hline Bravo & $0.046 \pm 0.005^{\mathrm{d}}$ & $0.193 \pm 0.009^{\mathrm{bcd}}$ & $0.106 \pm 0.008^{\mathrm{a}}$ & $0.253 \pm 0.037^{\mathrm{c}}$ & $0.077 \pm 0.003^{\mathrm{bc}}$ & $0.258 \pm 0.033^{\mathrm{cd}}$ \\
\hline Maestro & $0.066 \pm 0.002^{\mathrm{bc}}$ & $0.221 \pm 0.007^{\mathrm{ab}}$ & $0.086 \pm 0.003^{\mathrm{bc}}$ & $0.283 \pm 0.032^{\mathrm{bc}}$ & $0.065 \pm 0.001^{\mathrm{ef}}$ & $0.231 \pm 0.049^{\mathrm{d}}$ \\
\hline Lord & $0.047 \pm 0.004^{\mathrm{d}}$ & $0.199 \pm 0.028^{\mathrm{bcd}}$ & $0.091 \pm 0.005^{\mathrm{bc}}$ & $0.321 \pm 0.038^{\mathrm{bc}}$ & $0.080 \pm 0.001^{\mathrm{ab}}$ & $0.283 \pm 0.042^{\mathrm{abcd}}$ \\
\hline Osk 5.36/25-15 & $0.043 \pm 0.003^{\mathrm{d}}$ & $0.168 \pm 0.028^{\mathrm{d}}$ & $0.085 \pm 0.001^{\mathrm{cd}}$ & $0.378 \pm 0.034^{\mathrm{ab}}$ & $0.076 \pm 0.008^{\mathrm{bc}}$ & $0.238 \pm 0.053^{\mathrm{cd}}$ \\
\hline Mean & $0.058 \pm 0.012^{\mathrm{c}}$ & $0.213 \pm 0.310^{\mathrm{b}}$ & $0.086 \pm 0.012^{\mathrm{a}}$ & $0.305 \pm 0.790^{\mathrm{a}}$ & $0.071 \pm 0.010^{\mathrm{b}}$ & $0.280 \pm 0.440^{\mathrm{a}}$ \\
\hline
\end{tabular}

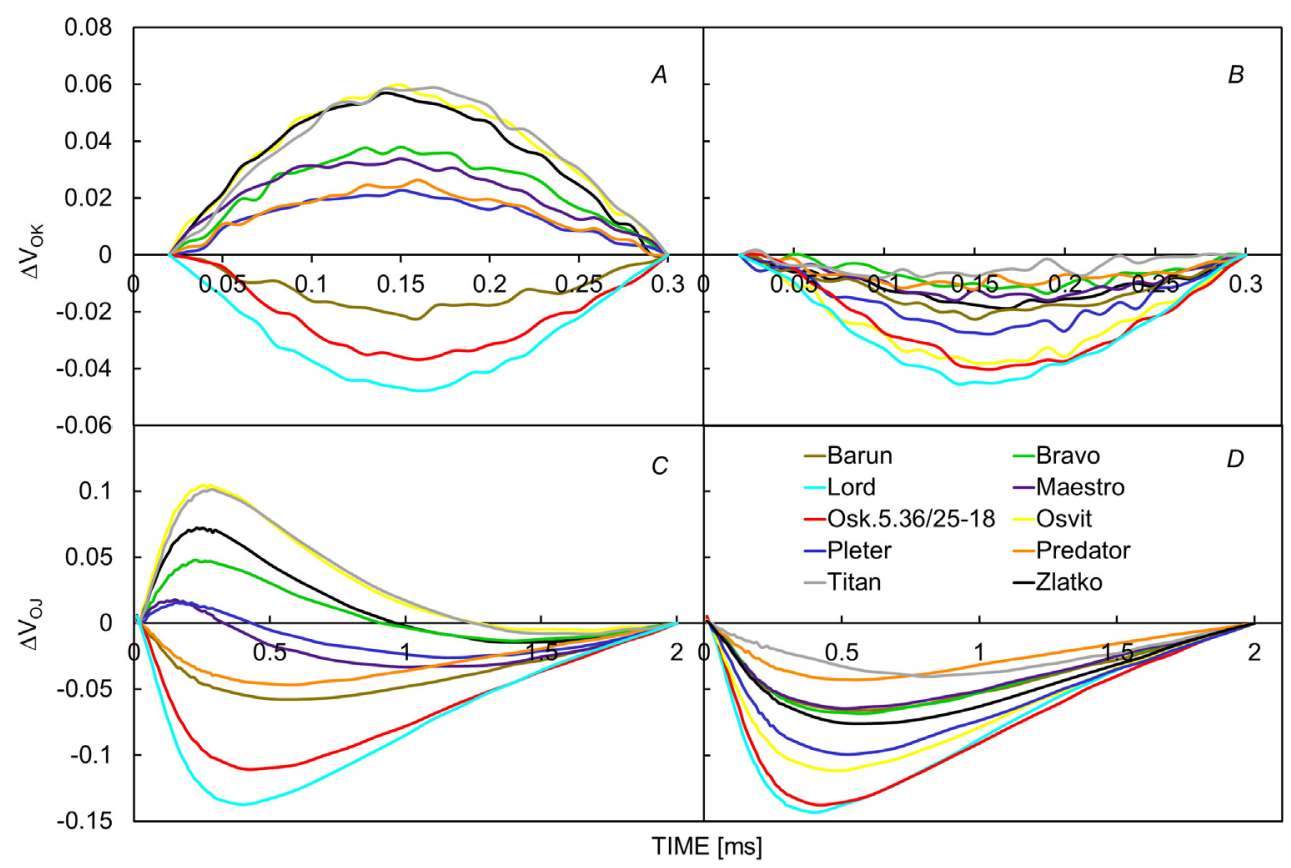

Fig. 1. Changes in the shape of the chlorophyll $a$ fluorescence transient curves for ten barley cultivars at anthesis $(A, C)$ and grain-filling stage $(B, D)$. Each curve represents average kinetics of 40 chosen technical replicates per genotype. Average fluorescence data were normalized between $\mathrm{O}$ and $\mathrm{K}$ steps (L-band; $A, B)$ and plotted as difference kinetics $\Delta \mathrm{W}_{\mathrm{OK}}=\mathrm{W}_{\mathrm{OK}}-\left(\mathrm{W}_{\mathrm{OK}}\right)_{\mathrm{ref}}$ in the $0.02-3$-ms time range. Fluorescence data normalized between $\mathrm{O}$ and $\mathrm{J}$ steps (K-band; $C, D)$ were plotted as difference kinetics $\Delta \mathrm{W}_{\mathrm{OJ}}=\mathrm{W}_{\mathrm{OJ}}-\left(\mathrm{W}_{\mathrm{OJ}}\right)_{\mathrm{ref}}$ in the $0.02-2$-ms time range. Average values measured in booting for each cultivar were used as referent value $\left(\mathrm{W}_{\mathrm{OK}}\right)_{\text {ref }}$ and $\left(\mathrm{W}_{\mathrm{OJ}}\right)_{\mathrm{ref}}$.

filling, genotypes Osk.5.36/25-15, Pleter, Lord, and Osvit can be distinguished as genotypes with the highest increase of $\Delta \mathrm{DF}_{\mathrm{ABS}}$ (Fig. 4B). At grain filling, the genotype Titan was the only genotype that displayed negative $\Delta \mathrm{DF}_{\mathrm{ABS}}$ that came from considerable decrease of all three parameters. The contributions of each partial driving force to $\triangle \mathrm{DF}_{\mathrm{ABS}}$ are shown in Table 4S (supplement).
Principal component analysis (PCA) was chosen to test whether the observed differences in photosynthetic efficiency between different growth stages were genotypespecific. The first two PCs in the booting stage explained $82.1 \%$ variation present in the dataset (Fig. $4 A$ ). During the booting, the lowest variability in performance was observed in Osk.5.36/25-15, Bravo, Lord, and Maestro. 

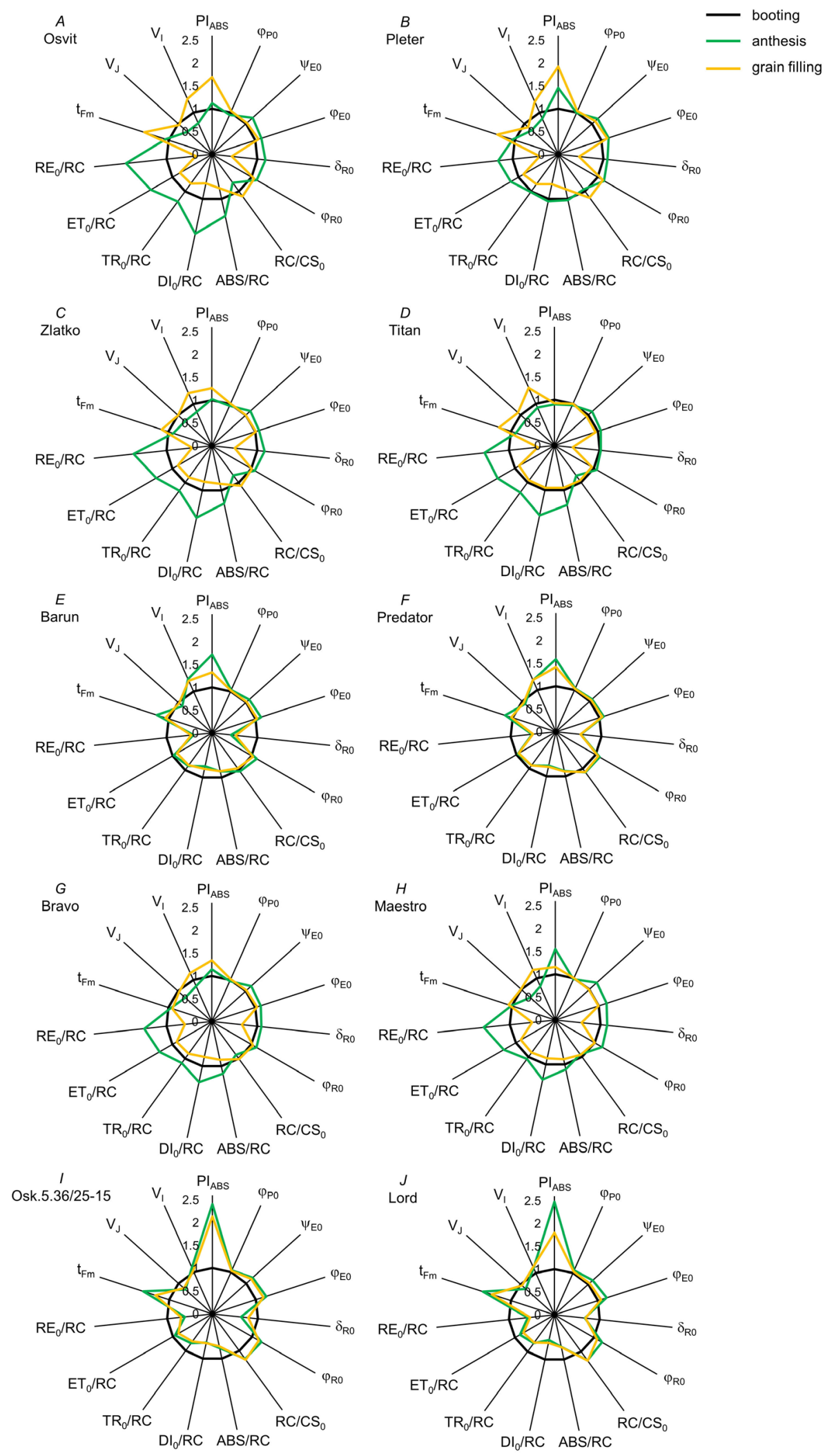

Fig. 2. Spider plots are showing normalized values of selected chlorophyll $a$ fluorescence parameters characterizing PSII functioning in ten barley cultivars at the anthesis and grain-filling stage. All values are shown as difference compared to the measurements in booting (booting =1). Each curve represents average kinetics of 40 chosen technical replicates per genotype. Raw data shown in the spider plots are presented in Table $3 \mathrm{~S}$ (supplement). 


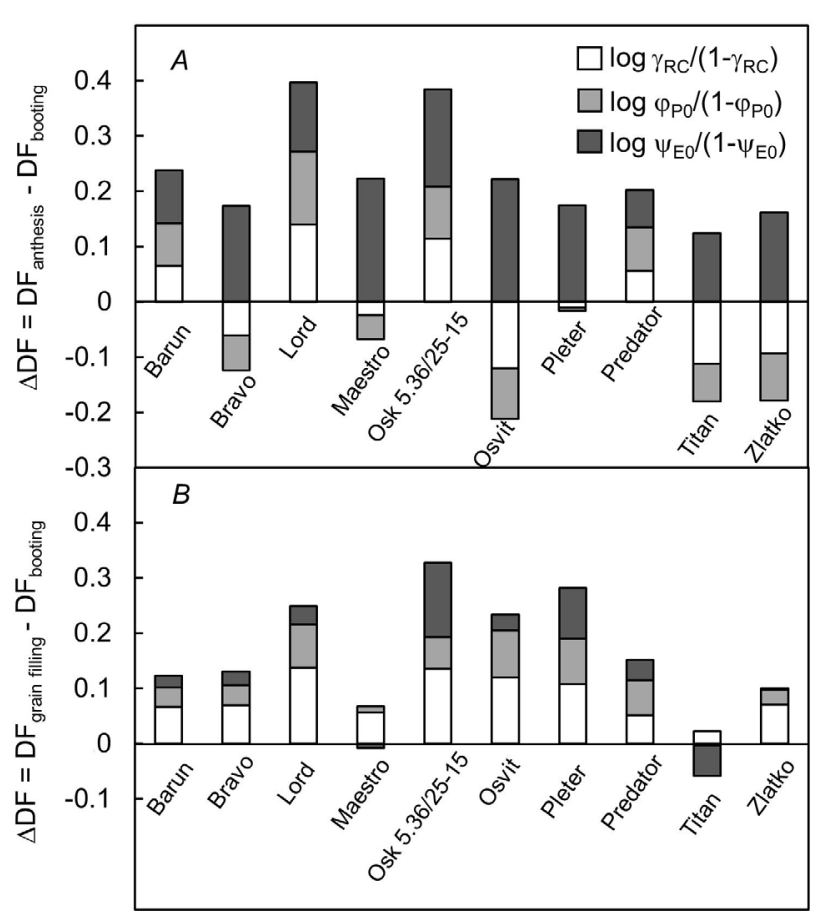

Fig. 3. Relative changes in the difference of driving forces $(\Delta D F)$ of ten barley cultivars, indicated as the difference of the DFs at the anthesis and grain-filling stage minus the DF in booting. Each DFABS is calculated by summing up their partial driving forces: $\log \gamma_{\mathrm{RC}} /\left(1-\gamma_{\mathrm{RC}}\right), \log \varphi_{\mathrm{P} 0} /\left(1-\varphi_{\mathrm{P} 0}\right)$, and $\log \psi_{\mathrm{E} 0} /\left(1-\psi_{\mathrm{E} 0}\right)$. Represented values are the mean of 40 chosen technical replicates per genotype.

Variation among the other six cultivars mostly overlapped, founding the genotype-specific reactions. Interestingly, all cultivars showing distinct reactions belonged to middlelate and late maturity groups. Relative to loadings of ChlF parameters, loading for grain yield was negligible in describing the variation between the cultivars at this stage (Table 5S, supplement).

ChlF and NDVI and grain yield explained $83.4 \%$ of the variation present among cultivars at anthesis in the first two PCs (Fig. 4B). PC analysis revealed two distinct photosynthetic reactions during the anthesis stage. Reactions of cultivars Osk.5.36/25-15, Bravo, Lord, and Maestro, tightly grouped in $\mathrm{PC} 1$, were the most defined by $\mathrm{PI}_{\mathrm{ABS}}, \mathrm{RC} / \mathrm{CS}_{0}, \varphi_{\mathrm{P} 0}, \mathrm{t}_{\mathrm{Fm}}$, and $\mathrm{V}_{\mathrm{J}}$. Grouping of cultivars at anthesis might have been influenced by the drought present at this stage contrasting two possible types of physiological responses to stress. PC2 was highly correlated to parameter $\varphi_{\mathrm{E} 0}$ representing the quantum yield of electron transport and grain yield. Relative importance of grain yield and NDVI in describing the variance between and among genotypes at anthesis was lower compared to all ChlF parameters analysed (Table 1). The relative importance of grain yield and NDVI in describing variation among and within cultivars was relatively the largest at the anthesis stage, compared to booting and grain filling (Table 1).

$\mathrm{ChlF}$ and agronomic parameters explained $79.0 \%$ of variation present among cultivars at the grain-filling stage
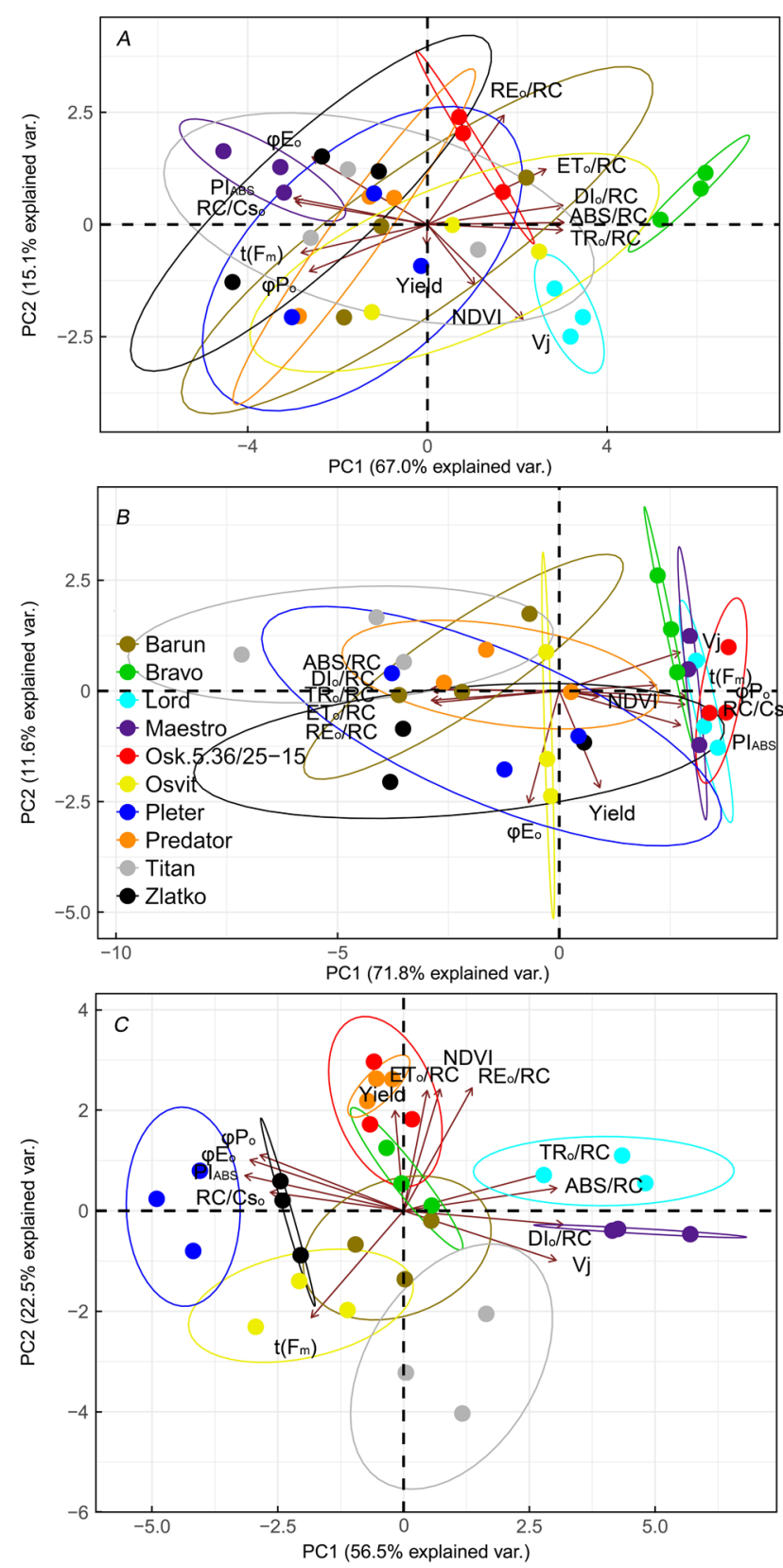

Fig. 4. Principal component analysis and the eigenvectors of the explanatory variables for the variation within and among ten barley genotypes at booting $(A)$, anthesis $(B)$, and grainfilling stage $(C)$. Points represent values for each plot (biological replicate, $n=30$ per stage).

in first two PCs (Fig. 4C). At grain filling, distinct reactions of all assessed cultivars were observed. Reactions of cultivars Lord and Maestro, positioned on the positive side of the PC1 were mostly determined by higher values of trapping, absorption and dissipation per reaction centre variable fluorescence at J step. Reactions of Osvit, Titan, and Barun were mostly determined by the high $\mathrm{t}_{\mathrm{FM}}$ values, and low values of $\mathrm{ET}_{0} / \mathrm{RC}, \mathrm{RE}_{0} / \mathrm{RC}, \mathrm{NDVI}$, and grain yield. The three of five best yielding cultivars (Predator, 
Osk.5.36/25-15, and Bravo) were grouped around the origin of $\mathrm{PC} 1$, and on the positive side of $\mathrm{PC} 2$, while the reactions of the other two cultivars (Pleter and Zlatko) were defined by the higher values of $\mathrm{PI}_{\mathrm{ABS}}, \varphi_{\mathrm{E} 0}, \varphi_{\mathrm{P} 0}$, and $\mathrm{RC} / \mathrm{CS}_{0}$, causing the shift towards the negative side of $\mathrm{PC} 1$.

Linear model between the logarithm of $\mathrm{ET}_{\mathbf{0}} / \mathrm{ABS}$ and PI $_{\text {ABS }}$ : Linear model between the logarithm of electron transport quantum yield $\left(\varphi_{\mathrm{E} 0}, \mathrm{ET}_{0} / \mathrm{ABS}\right)$ and logarithm of $\mathrm{PI}_{\mathrm{ABS}}$ relative to performance at the booting stage was set to test the relative contribution of electron transport quantum yield to performance index on absorption basis at the anthesis and grain-filling stage (Fig. 5), as relatively large effects of these parameters were observed in grouping of cultivars at anthesis and grain-filling stage. Data were normalized to the booting stage so that the differences between cultivar reactions would be more pronounced. Out of 800 data points, 696 or $87 \%$ were located in the positive quadrant of the graph, implying greater than zero values for logarithms of the two parameters relative to booting stage values. Linear relation between the logarithms of relative $\mathrm{PI}_{\mathrm{ABS}}$ and $\mathrm{ET}_{0} / \mathrm{ABS}$ was weaker at anthesis $\left(R^{2}\right.$ $=0.339)$ compared to the grain-filling stage $\left(R^{2}=0.921\right)$ representing smaller contribution of electron transport to performance index on absorption basis and a generally greater spread in performance. The variety Zlatko showed relatively the best overall performance that was consistent at both, anthesis and grain-filling stage, although there was the greater spread in performance observed at anthesis. Genotypes Bravo, Maestro, Osvit, Pleter, Titan, and Zlatko

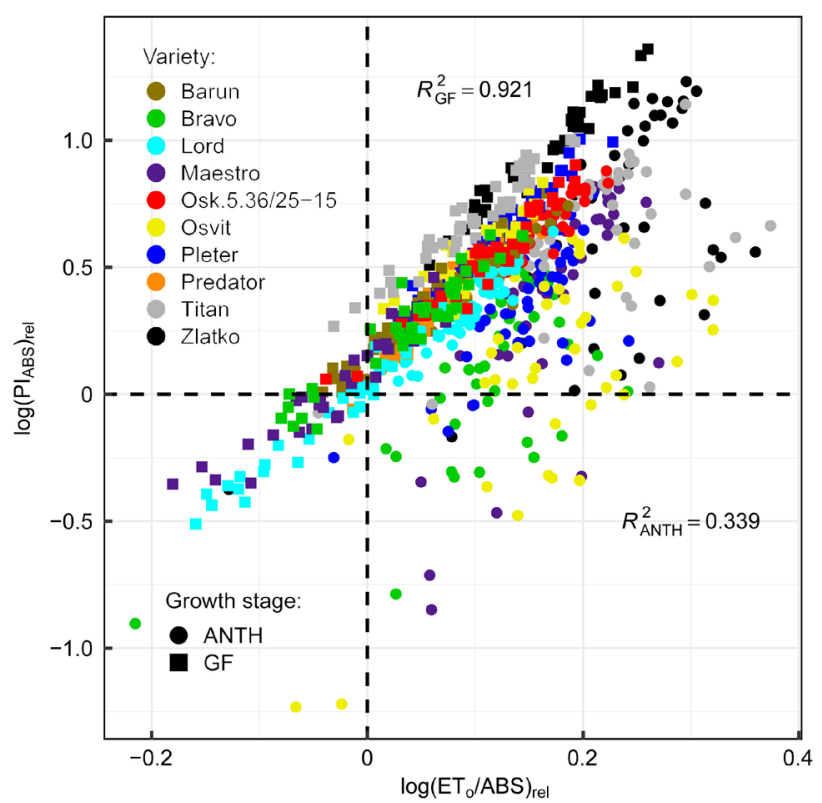

Fig. 5. Linear model between the logarithm of $\mathrm{ET}_{0} / \mathrm{ABS}$ and $\mathrm{PI}_{\mathrm{ABS}}$ at the anthesis (circle) and grain-filling stage (square) relative to the performance at booting stage (both normalized to booting stage). Data are the normalized values of 40 independently measured plant values at anthesis and grain-filling stage per barley cultivar normalized to the performance in booting $(n=$ $800)$. showed larger variation, and less linearity in relationship of logarithm of $\mathrm{PI}_{\mathrm{ABS}}$ and the logarithm of electron transport quantum yield (ET $/ \mathrm{ABS}$ ) at anthesis compared to grain filling. On the other hand, the genotypes Barun, Lord, and Osk.5.36/25-14 showed more linear relationships of the two parameters in both growth stages implying lower sensitivity to drought at anthesis. The most consistent relationships of logarithm of $\mathrm{PI}_{\mathrm{ABS}}$ and the logarithm of $\mathrm{ET}_{0} / \mathrm{ABS}$ at anthesis and grain-filling stage were observed in the genotypes Predator $\left(R_{A N T H}=0.958, R_{G F}=0.971\right)$, Lord $\left(R_{A N T H}=0.940, R_{G F}=0.982\right)$, Osk.5.36/25-15 $\left(R_{A N T H}=\right.$ $\left.0.911, R_{G F}=0.971\right)$, and Barun $\left(R_{A N T H}=0.867, R_{G F}=\right.$ 0.959) (data not shown).

Linear model of Chl $\boldsymbol{a}$ fluorescence parameters and NDVI: The overall PLS model between ChlF parameters and NDVI explained $78.5 \%$ of variance for NDVI $(R=$ $0.886)$, suggesting strong relationship between the two methods for assessment of plant performance (Fig. 6). However, the predictive ability of the model was higher in grain filling, when NDVI was able to differentiate the cultivars that have more green colour from the ones entering the senescence $(R=0.513)$ compared to booting and anthesis $(R=0.349)$ when there was less variability in greenness between the cultivars (Fig. 6) resulting in two-fold increase in proportion of explained variance for NDVI. Two groups visible on the graph represent the stages with higher greenness before the occurrence of senescence on the right and the grain filling in which senescence occurred on the left. The highest values of loadings in the model were observed for parameters $\varphi_{\mathrm{P} 0}$ (0.881), $\varphi_{\mathrm{E} 0}(0.352)$, and $\mathrm{V}_{\mathrm{J}}(0.240)$.

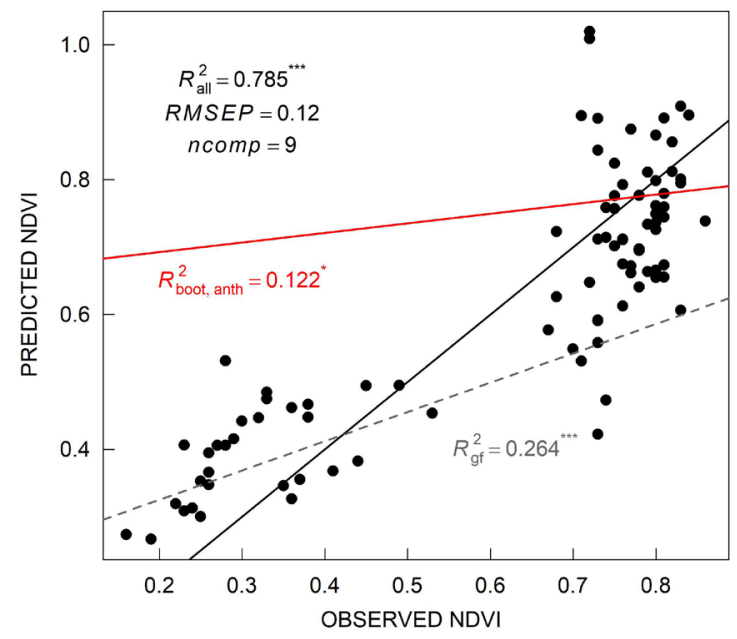

Fig. 6. Partial least squares model (PLS) of normalized difference vegetation index (NDVI) and chlorophyll $a$ fluorescence parameter. $R^{2}$ is a coefficient of determination, RMSEP root mean square error of prediction and ncomp number of components in PLS regression used after model calibration. Data represent the three biological replicates per genotype per stage $(n=90)$. The non-black $R^{2}$ values and regression lines represent the model predictive abilities for booting and anthesis (gray) and grain filling (red) NDVI performances. 


\section{Discussion}

Understanding the way plants adapt to changes of climate conditions is one of the major issues nowadays. The insight into complex networks of molecular interactions controlling plant acclimation could significantly improve chances of developing crops with an enhanced tolerance to field conditions. Climate change scenarios often assume increasing aridity in many regions around the world (Gratani et al. 2013). One of the goals of breeding process is to select barley cultivars with a better adaptation to diverse climate regimes. Here, we aimed to reveal response of selected winter barley genotypes to the mild drought stress that occurred during the growth season.

The assessed genotypes belonged to four maturity groups (Table 1S). Low but significant levels of NDVI variation between maturity groups can be seen at the grainfilling stage (Table 1) with the onset of senescence which is congruent with finding of Christopher et al. (2014). The highest mean levels of NDVI were obtained in the booting stage, cultivar Osk.5.36/25-15, a member of the late group of winter barley, having the highest NDVI value (Table 1). NDVI represents one of many vegetation indices extracted from spectral and hyperspectral peaks (Li et al. 2014, Din et al. 2017), such as green normalized difference vegetation index (GNDVI), normalized difference red edge index (NDRE), red edge chlorophyll index $\left(\mathrm{CI}_{\text {red edge }}\right)$, MERIS terrestrial chlorophyll index (MTCI), etc. However, as NDVI represents a reliable phenotype, correlated with grain yield, fit for integration into complex models, it could provide a valuable insight into adaptive mechanisms of crops (Duan et al. 2017). There is a strong negative correlation between dry matter content and relative water content in barley vegetative parts (Teulat et al. 1997). The highest dry matter content detected in our study indicated the lower water content in plant material at anthesis. The plausible cause of the high dry matter content at grain filling is the onset of senescence, as the vegetative barley parts are known to accumulate dry matter or lose water at grain filling (Lawlor et al. 1981, Dordas 2012).

The positive correlations between the NDVI indexes and the leaf nitrogen content were reported in wheat (Hansen and Schjoerring 2003, Cabrera-Bosquet et al. 2011), and maize (Freeman et al. 2007). NDVI indexes are known to be convenient in assessment of plant Chl content (Gitelson and Merzlyak 1997), which implies the existence of correlations between $\mathrm{N}$ content and NDVI as $\mathrm{Chl}$ molecules are rich in $\mathrm{N}$. Conversely, the negative correlations were observed between the $\mathrm{C}$ content and $\mathrm{C} / \mathrm{N}$ ratio (Tables $6 \mathrm{~S}, 7 \mathrm{~S}$; supplement). Negative correlations between the reflectance indices in the proximate spectral peaks as NDVI and wheat and barley $\mathrm{C} / \mathrm{N}$ ratio were reported before (Xu et al. 2015, 2018). The plausible cause of this negative correlation is the relative expression of $\mathrm{C}$ content as percentage. As the leaf enters the senescence, protein degradation occurs, and the nitrogen content decreases with the increase in activity of carboxypeptidases and proteases (Parrott et al. 2005). Carbohydrate accumulation in leaves presents another clear sign signalling the onset of senescence (Parrott et al. 2007, Distelfeld et al. 2014).
Both of these processes imply the increase in relative proportion of carbon in faster senescing leaves compared to the leaves of the cultivars showing a more stay-green effect (Thomas and Ougham 2014).

The JIP-test was used here to track changes of the light-dependent reactions of the photosynthesis through three developmental stages in the field where plants were exposed to direct changes of environmental conditions. The rise of induction curves during first 2-3 ms is associated with primary photochemistry, namely, the light reactions of photosynthesis (Oukarroum et al. 2007). This is the rise from initial fluorescence $\left(\mathrm{F}_{0}\right)$ to first intermediate step $(\mathrm{J})$ at $2 \mathrm{~ms}$. The $\mathrm{O}-\mathrm{J}$ normalization exposes two additional steps, one at about $150 \mu \mathrm{s}$ (L-band) and another at about $300 \mu \mathrm{s}$ (K-band) (Strauss et al. 2006, Yusuf et al. 2010). Seven out of ten barley genotypes showed positive while only three genotypes (Barun, Osk.5.36/25-15, and Lord) revealed negative L-band at anthesis. The shape of L-band is influenced by the transfer of the excitation energy between antennae and reaction centres of PSII (Yusuf et al. 2010). Negative values indicated a better utilization of the excitation energy and higher stability due to better connectivity between PSII units in three genotypes. Positive values of L-band suggested a lower energetic connectivity and poor stability of the system in seven genotypes at anthesis that could be the consequence of mild drought stress. It has been shown that drought stress causes changes in PSII photochemistry, which could be connected to reorganisation and stability reduction of thylakoid membranes by declining the levels of PSII proteins, especially those in PSII antennae (Chen et al. 2016, Liu et al. 2019) directly affecting connectivity and stability of PSII.

Further, the K-band is known to be a very good indicator of various stressful conditions, especially drought (Oukarroum et al. 2007, Jedmowski et al. 2013, Daszkowska-Golec et al. 2019). Six out of ten genotypes revealed positive inflections of the K-band at anthesis. Positive values are associated with inactivation of oxygen-evolving complex (OEC) and/or the increase of functional antenna size (Kalaji et al. 2018). It was shown that manganese cluster of PSII presents very sensitive component of the electron transport chain (Oukarroum et al. 2009, Kalaji et al. 2016). Dissociation of the OEC facilitates donation of electrons to PSII by alternative internal electron donor, such as proline, which can be observed as positive K-band due to the temporary increase in the reduced $\mathrm{Pheo}^{-} / \mathrm{Q}_{\mathrm{A}}{ }^{-}$concentration (De Ronde et al. 2004). In our study, the mild drought at anthesis led to the induction of proline accumulation (Table 2). Proline is the amino acid included in the plant osmotic stress response, and the current plant proline concentrations are the result of the interplay of biosynthesis, degradation and interand intracellular transportation (Lehmann et al. 2010). Nevertheless, proline synthesis can also be a result of plant developmental stage and higher concentrations of proline can be expected in generative plant parts during flowering (Kavi Kishor et al. 2015). In addition, a recent study showed that the positive K-band is also associated with downregulation of genes encoding $P s b C, P s b E$ which play 
a significant role in attaching PsbO to OEC in response to drought in two barley cultivars (Daszkowska-Golec et al. 2019). These results corroborate our findings and suggest impaired electron flow between the OEC and the acceptor side of the PSII RC in six barley genotypes.

Negative K-band values, however, were often recognized as the sign of tolerance to stressful conditions (Krüger et al. 2014, Żurek et al. 2014, Begović et al. 2016). Furthermore, Vankatesh et al. (2012) reported that negative K-band indicates an intactness of functional PSII antenna size. Functional PSII antennae combined with good connectivity between PSII units (negative L-band) results in greater stability of the system what leads to better feeding of reaction centres with excitation energy and consequently to better energy conservation through electron transport (Yusuf et al. 2010, Venkatesh et al. 2012). Therefore, negative K-bands observed in Barun, Osk.5.36/25-15, Predator, and Lord genotypes suggested that maintaining functional PSII antennae might be the effective mechanism to cope with limited water conditions in the field at this stage. All ten genotypes at grain filling revealed the negative L- and K-bands suggesting that connectivity between functional PSII antennae and RCs led to operating electron transport what in the long run generated efficient utilization of excitation energy.

Parameters of the JIP-test are often used to identify the main targets of stress action (Yusuf et al. 2010, Kalaji et al. 2018). It represents the stepwise energy flow through the PSII (Strasser et al. 2004). The PSII is known to be extremely sensitive to changes in environmental conditions. The activity of PSII in unfavourable environmental conditions reduces faster than many other physiological processes (Murata et al. 2007). The PSII protein complex is composed from numerous subunits involved in different parts of primary photochemistry, such as water-plastoquinone oxidoreduction, harvesting, and trapping of the light, and transport of the electrons in electron transport chain. Number of those proteins become phosphorylated in stressful conditions what is usually involved in recovery from photoinhibition (Chen et al. 2009). Recent study showed that activity of PSII decreases when plants are exposed to drought due to the decrease of active RCs and most OJIP parameters are very sensitive to changes in relative water content (RWC) in wheat leaves (Rapacz et al. 2019). However, molecular mechanism that regulates events from acclimation, photoinhibition, and recovery in stressful conditions still remains unknown. Further, the performance index, $\mathrm{PI}_{\mathrm{ABS}}$ (Fig. $2 A, J$ ) is known to be very responsive parameter to the water status of the plant (Oukarroum et al. 2007, Živčák et al. 2008). The early genotypes, Osvit, Zlatko, and Pleter as well as midlate Bravo showed slight, but continuous increase from booting to grain filling. Increase in $\mathrm{PI}_{\mathrm{ABS}}$ can be attributed to changes in electron fluxes, as the flux ratios tend to increase with leaf age following the increase in the $\mathrm{Chl}$ content (Jiang et al. 2006, Mlinarić et al. 2017). Relative changes in each partial driving force (DF) enabled us to approximate the contribution of each parameter to the change of $\mathrm{PI}_{\mathrm{ABS}}$. The increase of $\mathrm{PI}_{\mathrm{ABS}}$ at anthesis came mainly from the increase in partial DF of conversion of excitation energy to electron transport further than $\mathrm{Q}_{\mathrm{A}}$, $\Delta \log \psi_{\mathrm{E} 0} /\left(1-\psi_{\mathrm{E} 0}\right)$ compared to booting. At grain filling, the increase in other two partial DFs, reaction centre density of all PSII Chls, $\Delta \log \gamma_{\mathrm{RC}} /\left(1-\gamma_{\mathrm{RC}}\right)$, and primary photochemistry due to the light reactions, $\Delta \log \varphi_{\mathrm{P} 0} /\left(1-\varphi_{\mathrm{P} 0}\right)$ contributed the most to the continuous increase of $\mathrm{PI}_{\mathrm{ABS}}$ compared to booting. Other genotypes (except for Titan) showed the highest values of this parameter at anthesis what came mainly from the increase of $\Delta \log \psi_{\mathrm{E} 0} /(1-$ $\left.\psi_{\mathrm{E} 0}\right)$. The genotype Titan was the only one that exhibited decrease of $\mathrm{PI}_{\mathrm{ABS}}$ after booting due to the decrease in partial DFs, $\Delta \log \varphi_{\mathrm{P} 0} /\left(1-\varphi_{\mathrm{P} 0}\right)$ and $\Delta \log \psi_{\mathrm{E} 0} /\left(1-\psi_{\mathrm{E} 0}\right)$, respectively. The increase in conversion of excitation energy to electron transport further than $\mathrm{Q}_{\mathrm{A}}$ in most genotypes at anthesis was further supported by the increase of electron transport $\left(\varphi_{\mathrm{E} 0}\right)$ and the efficiency that an electron moves further than $\mathrm{Q}_{\mathrm{A}}^{-}\left(\psi_{\mathrm{E} 0}\right)$. In addition, the quantum yield for reduction of end electron acceptors at the PSI acceptor side $\left(\varphi_{\text {RE } 0}\right)$ increased, which suggested that cyclic electron flow was generated around PSI (Oukarroum et al. 2009, Ceppi et al. 2012, Huang et al. 2018). The increase of $\psi_{\mathrm{E} 0}$ implies that efficient electron transport is achieved despite the lower amount of precipitation during anthesis, which could be due to the higher contents of proline detected at anthesis in barley cultivars (Table 2) and protective role of proline previously described.

Quite accurate insight into PSII functioning can be obtained through the changes in specific fluxes per $\mathrm{RC}$ since only active $\mathrm{RCs}$ that can reduce $\mathrm{Q}_{\mathrm{A}}$ are considered (Force et al. 2003, Strasser et al. 2004). The decrease of quantum yield of electron trapping $\left(\varphi_{\mathrm{P} 0}\right)$ in Osvit, Zlatko, Bravo, Maestro, Pleter, and Titan at anthesis was followed by the increase of $\mathrm{ABS} / \mathrm{RC}$ and $\mathrm{TR}_{0} / \mathrm{RC}$ what suggested that certain part of RCs was inactivated due to inhibited OEC. Most of the active RCs were transformed to 'silent' ones that cannot reduce $\mathrm{Q}_{\mathrm{A}}$ (Strasser et al. 2004, Yusuf et al. 2010). Excess excitation energy is normally dissipated as heat, which was confirmed with the increase of $\mathrm{DI}_{0} / \mathrm{RC}$ in those genotypes. It has been demonstrated recently that dissipation of excess light energy in stressful conditions decreases efficiency of photochemical reactions (Chen et al. 2016). This corroborates our finding since the reduction in $\varphi_{\mathrm{P} 0}$ could be connected to the increase of energy dissipation under mild drought stress in our study. The simultaneous increase of $\mathrm{ET}_{0} / \mathrm{RC}, \mathrm{RE}_{0} / \mathrm{RC}$, and $\delta_{\mathrm{RE} 0}$ indicated that these genotypes could be rather unaffected by water deficit at anthesis. Genotypes Barun, Predator, Lord, and Osk.5.36/25-15 showed the increase of $\varphi_{\mathrm{P} 0}$, followed by decrease of $A B S / R C, \mathrm{TR}_{0} / \mathrm{RC}, \mathrm{DI}_{0} / \mathrm{RC}$, and $\mathrm{RE}_{0} / \mathrm{RC}$. At the same time, $\mathrm{ET}_{0} / \mathrm{RC}$ remained unchanged, suggesting better resistance to the water deficit stress at anthesis. On the other hand, at grain filling, nine out of ten genotypes (except for Titan) revealed the decrease of all specific fluxes at grain filling compared to booting. The decline in $\mathrm{ABS} / \mathrm{RC}$ suggested that all genotypes possess rather efficient mechanism to regulate the amount of excitation energy needed to reach $\mathrm{RC}$. The decline in $\mathrm{TR}_{0} / \mathrm{RC}$ consequently resulted in reduced $\mathrm{ET}_{0} / \mathrm{RC}$ as well as $\mathrm{RE}_{0} / \mathrm{RC}$ due to lower amount of trapped energy and not from reduction of electron transport capacity $\psi_{\mathrm{E} 0}$. The fact that 
$\mathrm{DI}_{0} / \mathrm{RC}$ also declined at grain filling suggested that all trapped energy was efficiently utilized in electron transport chain. The genotype Titan, however, showed the decline in $\mathrm{ET}_{0} / \mathrm{RC}$ and $\mathrm{RE}_{0} / \mathrm{RC}$, but did not show changes in $\mathrm{ABS} / \mathrm{RC}, \mathrm{TR}_{0} / \mathrm{RC}$, and $\mathrm{DI}_{0} / \mathrm{RC}$ compared to booting. In addition, Titan was the only genotype that showed the decrease of $\mathrm{PI}_{\mathrm{ABS}}$ mostly due to the decrease of $\Delta \log \psi_{\mathrm{E} 0} /$ $\left(1-\psi_{\mathrm{E} 0}\right)$, indicating that this cultivar showed considerable sensitivity to the given field conditions.

In PCA of ChlF and agronomic parameters, distinct reactions of genotypes at the booting stage can be attributed to genotype differences in maturity (Fig. 4A). All four genotypes that showed distinct reactions at booting belong to middle-late and late maturity groups. At anthesis, genotypes Osk.5.36/25-15, Lord, Bravo, and Maestro maintained high values of performance index on absorption basis due to maintaining high values of $\varphi_{\mathrm{P} 0}$ suggesting that the PSII photochemistry of these cultivars was not alleviated by drought stress. Higher loadings of $\mathrm{RC} / \mathrm{CS}_{0}$ and $\mathrm{t}_{\mathrm{Fm}}$ also suggest maintenance of high performance of the PSII. The higher fluorescence intensity at $\mathbf{J}$ step in this group suggested the decrease in electron transport beyond $\mathrm{Q}_{\mathrm{A}}^{-}$(Redillas et al. 2011). The cultivars that maintained high values of electron fluxes and performance indexes at grain-filling stage were the ones that showed relatively the highest grain yields, and were all grouped in the same quadrant (Fig. 4C). The relative performance of these cultivars was probably defined with slower leaf senescence compared to other five cultivars also confirmed by higher NDVI values (Table 1). In environments facilitating prolonged grain filling, the higher NDVI values can represent advantage in terms of yield formation (Marinaccio et al. 2015). Earlier onset of senescence and degradation of plastid proteome is also linked to degradation of photosynthetic pigments, poorer performance in nutrient reutilization, and consequently lower grain yield (Distelfeld et al. 2014, Viljevac Vuletić and Španić 2020). All of the cultivars represented in this study are high-yielding varieties by breeding standards. However, there were some differences especially in the lower yielding genotype Osvit being a hulless type. Based on the present results, two types of mechanisms of coping with stress at anthesis that can be suggested. The first one can be observed in genotypes Osk5.36/25-15, Bravo, and Predator that maintain highly functional electron transport during the mild drought at anthesis throughout the grainfilling stage. The second one can be seen in genotypes Pleter and Zlatko that showed the drop in efficiency of electron transport at anthesis followed by catch-up phase at the grain-filling stage.

The linear model between the logarithm of electron transport quantum yield $\left(\varphi_{\mathrm{E} 0}, \mathrm{ET}_{0} / \mathrm{ABS}\right)$ and logarithm of $\mathrm{PI}_{\mathrm{ABS}}$ revealed that most samples showed better vitality after the booting (Fig. 5). This was probably caused by maturing and successive increase in the density of leaf active RCs. Plants are expected to have lower values of fluorescence parameters, such as $\varphi_{\mathrm{P} 0}$, at earlier growth stage (Wu et al. 2015), and the photosynthetic performance is expected to decline sometime after anthesis, as leaves enter the senescence (Humbeck and Krupinska 2003).
Generally, the electron transport determined the change in plant performance more at grain filling than that at anthesis. Two of the cultivars, Predator and Osk.5.36/25-15, showed the highest consistency in this function between the growth phases, while the importance of electron transport in performance index of cultivar Lord dramatically declined at grain filling with the onset of senescence. The two properties of the relationship of logarithm of $\mathrm{ET}_{0} / \mathrm{ABS}$ and logarithm of $\mathrm{PI}_{\mathrm{ABS}}$ that seem to play the major role in determining the plant overall performance appear to be position or the ranking in the plot (Christen et al. 2007, Oukarroum et al. 2007, Franić et al. 2020) and consistency in performance between phases. The most consistent cultivars between growth stages (Predator, Lord, Osk.5.36/25-15, and Barun) were also identified as the ones with negative $\mathrm{L}$ and $\mathrm{K}$ amplitudes indicating the lower sensitivity to drought at anthesis. Despite the change in importance of electron transport between phases, the position of cultivar Zlatko indicated best photosynthetic performance in both stages, which was accompanied by the second highest grain yield. However, consistency of determined relationships in Zlatko was low $\left(R_{A N T H}=0.494\right.$, $R_{G F}=0.972$ ). The most consistent genotype in performance between the stages (Predator) showed the highest grain yield. As a rule of thumb, the quantitative criteria in selection for drought tolerance could be proposed as the correlations between logarithm of $\mathrm{ET}_{0} / \mathrm{ABS}$ and logarithm of $\mathrm{PI}_{\mathrm{ABS}}$ at anthesis and grain filling larger then 0.85 , along with the negative values of L- and K-bands.

According to the previous results showing predictive value of ChlF, the partial least squares model predicting NDVI from fluorescence data used for PC analysis was constructed (Goltsev et al. 2012, Galić et al. 2020). Positive loading values for parameters assessing the quantum yields of the electron transport and variable fluorescence at J step were detected in model describing the variation in NDVI. The parameter NDVI is known as a function of PAR intercepting the leaf surface, while ChlF parameters were shown to react to different intensities of PAR (Kalaji et al. 2012). Furthermore, this is in accordance with findings of Kucharewicz et al. (2017) in barley, Panda and Sarkar (2013) and Zhang et al. (2015) in rice, and Zhang et al. (2012) in maize. Parameters assessing the electron transport can feasibly differentiate cultivars with faster and slower senescence what is in accordance with the ability of NDVI to measure the crop 'greenness', indicating the overall quantity of tissues able to perform photosynthesis. This also corroborates the higher predictive accuracies of the model in our study for grain filling NDVI performance compared to performances in booting and anthesis. However, in our study, it was not confirmed that NDVI was useful parameter to screen barley cultivars for stress tolerance.

In conclusion, instability of PSII observed as slight disruption of oxygen-evolving complex (K-band) and lower energetic connectivity (L-band) were induced by lower amount of rainfall at anthesis. Nevertheless, the increased electron transport beyond primary acceptor $\mathrm{Q}_{\mathrm{A}}$ contributed the most to the increased $\mathrm{PI}_{\mathrm{ABS}}$ values in majority of genotypes at anthesis. However, the stabilization and increase 
of energetic connectivity within PSII was observed at the grain-filling stage. Furthermore, the increase of $\mathrm{PI}_{\mathrm{ABS}}$ at the grain-filling stage can be attributed to the increase of density of reaction centres per chlorophyll. Based on the obtained results, we can conclude that: (1) two types of barley genotypes can be distinguished by the response to mild drought stress at anthesis: the ones that maintain the high photosynthetic efficiency during the mild drought and the ones in which the drop in photosynthetic per-formance during mild drought was followed by the increase in photosynthetic performance, and (2) the NDVI could provide valuable information about photosynthetic performance with respect to the ability of NDVI to measure the overall 'greenness' thus separating the cultivars displaying more the 'stay-green' effect from those entering leaf senescence consequently reducing their photosynthetic performance. However, use of ChlF offers some advantages over NDVI due to the higher information resolution, ability to detect stress and biophysical interpretation of parameters providing a biological framework to the barley breeding programs.

\section{References}

Ahuja I., de Vos R.C.H., Bones A.M., Hall R.D.: Plant molecular stress responses face climate change. - Trends Plant Sci. 15: 664-674, 2010

Araus J.L., Cairns J.E.: Field high-throughput phenotyping: the new crop breeding frontier. - Trends Plant. Sci. 19: 52-61, 2014.

Badr A., Müller K., Schäfer-Pregl R. et al.: On the origin and domestication history of barley (Hordeum vulgare). - Mol. Biol. Evol. 17: 499-510, 2000.

Begović L., Mlinarić S., Antunović Dunić J. et al.: Response of Lemna minor L. to short-term cobalt exposure: The effect on photosynthetic electron transport chain and induction of oxidative damage. - Aquat. Toxicol. 175: 117-126, 2016.

Brestič M., Živčák M., Hauptvogel P. et al.: Wheat plant selection for high yields entailed improvement of leaf anatomical and biochemical traits including tolerance to non-optimal temperature conditions. - Photosynth. Res. 136: 245-255, 2018.

Bro R., Smilde A.K.: Principal component analysis. - Anal. Methods-UK 6: 2812-2831, 2014.

Cabrera-Bosquet L., Molero G., Stellacci A. et al.: NDVI as a potential tool for predicting biomass, plant nitrogen content and growth in wheat genotypes subjected to different water and nitrogen conditions. - Cereal Res. Commun. 39: 147-159, 2011.

Carillo P., Gibon Y.: Protocol: extraction and determination of proline, 2011. Available at: https://www.researchgate.net/ publication/211353600_PROTOCOL_Extraction_and determination_of_proline.

Cassman K.G., Grassini P., van Wart J.: Crop yield potential, yield trends, and global food security in a changing climate. In: Hillel D., Rosenzweig C. (ed.): Handbook of Climate Change and Agroecosystems: Impacts, Adaptation, and Mitigation. Pp. 37-51. World Scientific, Singapore 2011.

Cavender-Bares J., Bazzaz F.A.: From leaves to ecosystems: using chlorophyll fluorescence to assess photosynthesis and plant function in ecological studies. - In: Papageorgiou G.C., Govindjee (ed.): Chlorophyll $a$ Fluorescence: A Signature of Photosynthesis. Advances in Photosynthesis and Respiration. Pp. 737-755. Springer, Dordrecht 2004.
Ceppi M.G., Oukarroum A., Çiçek N. et al.: The IP amplitude of the fluorescence rise OJIP is sensitive to changes in the photosystem I content of leaves: a study on plants exposed to magnesium and sulfate deficiencies, drought stress and salt stress. - Physiol. Plantarum 144: 277-288, 2012.

Chen Y.-E., Liu W.-J., Su Y.-Q. et al.: Different response of photosystem II to short and long-term drought stress in Arabidopsis thaliana. - Physiol. Plantarum 158: 225-235, 2016.

Chen Y.-E., Yuan S., Du J.-B. et al:: Phosphorylation of photosynthetic antenna protein CP29 and photosystem II structure changes in monocotyledonous plants under environmental stresses. - Biochemistry 48: 9757-9763, 2009.

Christen D., Schönmann S., Jermini M. et al.: Characterization and early detection of grapevine (Vitis vinifera) stress responses to esca disease by in situ chlorophyll fluorescence and comparison with drought stress. - Environ. Exp. Bot. 60: 504-514, 2007.

Christopher J.T., Veyradier M., Borrell A.K. et al.: Phenotyping novel stay-green traits to capture genetic variation in senescence dynamics. - Funct. Plant. Biol. 41: 1035-1048, 2014.

Daszkowska-Golec A., Collin A., Sitko K. et al.: Genetic and physiological dissection of photosynthesis in barley exposed to drought stress. - Int. J. Mol. Sci. 20: 6341, 2019.

De Ronde J.A., Cress W.A., Krüger G.H.J. et al.: Photosynthetic response of transgenic soybean plants, containing an Arabidopsis P5CR gene, during heat and drought stress. J. Plant Physiol. 161: 1211-1224, 2004.

Din M., Zheng W., Rashid M. et al.: Evaluating hyperspectral vegetation indices for leaf area index estimation of Oryza sativa L. at diverse phenological stages. - Front. Plant Sci. 8: $820,2017$.

Distelfeld A., Avni R., Fischer A.M.: Senescence, nutrient remobilization, and yield in wheat and barley. - J. Exp. Bot. 65: 3783-3798, 2014

Dordas C.: Variation in dry matter and nitrogen accumulation and remobilization in barley as affected by fertilization, cultivar, and source-sink relations. - Eur. J. Agron. 37: 31-42, 2012.

Duan T., Chapman S., Guo Y., Zheng B.: Dynamic monitoring of NDVI in wheat agronomy and breeding trials using an unmanned aerial vehicle. - Field Crop. Res. 210: 71-80, 2017.

Force L., Critchley C., van Rensen J.J.S.: New fluorescence parameters for monitoring photosynthesis in plants. Photosynth. Res. 78: 17-33, 2003.

Franić M., Jambrović A., Šimić D. et al:: Photosynthetic properties of maize hybrids under different environmental conditions probed by the chlorophyll $a$ fluorescence. Maydica 64: M25, 2020.

Freeman K.W., Girma K., Arnall D.B. et al.: By-plant prediction of corn forage biomass and nitrogen uptake at various growth stages using remote sensing and plant height. - Agron. J. 99: 530-536, 2007.

Galić V., Mazur M., Šimić D. et al.: Plant biomass in salt-stressed young maize plants can be modelled with photosynthetic performance. - Photosynthetica 57: 9-19, 2020.

Gitelson A.A., Merzlyak M.N.: Remote estimation of chlorophyll content in higher plant leaves. - Int. J. Remote Sens. 18: 2691-2697, 1997.

Goltsev V., Zaharieva I., Chernev P. et al:: Drought-induced modifications of photosynthetic electron transport in intact leaves: analysis and use of neural networks as a tool for a rapid non-invasive estimation. - BBA-Bioenergetics 1817: 1490-1498, 2012.

Gratani L., Catoni R., Varone L.: Morphological, anatomical and physiological leaf traits of $Q$. ilex, $P$. latifolia, $P$. lentiscus, 
and $M$. communis and their response to Mediterranean climate stress factors. - Bot. Stud. 54: 35, 2013.

Hanjra M.A., Qureshi M.E.: Global water crisis and future food security in an era of climate change. - Food Policy 35: 365$377,2010$.

Hansen P.M., Schjoerring J.K.: Reflectance measurement of canopy biomass and nitrogen status in wheat crops using normalized difference vegetation indices and partial least squares regression. - Remote Sens. Environ. 86: 542-553, 2003.

Huang W., Yang Y.-J., Zhang S.-B., Liu T.: Cyclic electron flow around photosystem I promotes ATP synthesis possibly helping the rapid repair of photodamaged photosystem II at low light. - Front. Plant Sci. 9: 239, 2018.

Humbeck K., Krupinska K.: The abundance of minor chlorophyll $a / b$ binding proteins CP29 and LHCI of barley (Hordeum vulgare L.) during leaf senescence is controlled by light. J. Exp. Bot. 54: 375-383, 2003.

Jedmowski C., Ashoub A., Brüggemann W.: Reactions of Egyptian landraces of Hordeum vulgare and Sorghum bicolor to drought stress, evaluated by the OJIP fluorescence transient analysis. - Acta Physiol. Plant. 35: 345-354, 2013.

Jiang C.-D., Jiang G.-M., Wang X. et al.: Increased photosynthetic activities and thermostability of photosystem II with leaf development of elm seedlings (Ulmus pumila) probed by the fast fluorescence rise OJIP. - Environ. Exp. Bot. 58: 261-268, 2006.

Kalaji H.M., Carpentier R., Allakhverdiev S.I., Bosa K.: Fluorescence parameters as early indicators of light stress in barley. J. Photoch. Photobio. B 112: 1-6, 2012.

Kalaji H.M., Govindjee, Bosa K. et al.: Effects of salt stress on photosystem II efficiency and $\mathrm{CO}_{2}$ assimilation of two Syrian barley landraces. - Environ. Exp. Bot. 73: 64-72, 2011.

Kalaji H.M., Guo P.: Chlorophyll fluorescence: a useful tool in barley plant breeding programs. - In: Sánchez A., Gutierrez S.J. (ed.): Photochemistry Research Progress. Pp. 439-463. Nova Science Publishers, Hauppauge 2008.

Kalaji H.M., Jajoo A., Oukarroum A. et al.: Chlorophyll a fluorescence as a tool to monitor physiological status of plants under abiotic stress conditions. - Acta Physiol. Plant. 38: 102, 2016.

Kalaji H.M., Rastogi A., Živčák M. et al.: Prompt chlorophyll fluorescence as a tool for crop phenotyping: an example of barley landraces exposed to various abiotic stress factors. Photosynthetica 56: 953-961, 2018.

Kavi Kishor P.B., Hima Kumari P., Sunita M.S.L., Sreenivasulu N.: Role of proline in cell wall synthesis and plant development and its implications in plant ontogeny. - Front. Plant Sci. 6: 544, 2015.

Krüger G.H.J., De Villiers M.F., Strauss A.J. et al.: Inhibition of photosystem II activities in soybean (Glycine max) genotypes differing in chilling sensitivity. - S. Afr. J. Bot. 95: 85-96, 2014.

Kucharewicz W., Distelfeld A., Bilger W. et al.: Acceleration of leaf senescence is slowed down in transgenic barley plants deficient in the DNA/RNA-binding protein WHIRLY1. J. Exp. Bot. 68: 983-996, 2017.

Lalić A., Novoselović D., Kovačević J. et al:: Genetic gain and selection criteria effects on yield and yield components in barley (Hordeum vulgare L.). - Period. Biol. 112: 311-316, 2010.

Lawlor D.W.: Carbon and nitrogen assimilation in relation to yield: mechanisms are the key to understanding production systems. - J. Exp. Bot. 53: 773-787, 2002.

Lawlor D.W., Day W., Johnston A.E. et al.: Growth of spring barley under drought: crop development, photosynthesis, dry- matter accumulation and nutrient content. - J. Agr. Sci. 96: 167-186, 1981.

Lehmann S., Funck D., Szabados L., Rentsch D.: Proline metabolism and transport in plant development. - Amino Acids 39: 949-962, 2010.

Li F., Miao Y., Feng G. et al.: Improving estimation of summer maize nitrogen status with red edge-based spectral vegetation indices. - Field Crop. Res. 157: 111-123, 2014.

Lichtenthaler H., Wenzel O., Buschmann C., Gitelson A.: Plant stress detection by reflectance and fluorescence. - Ann. N. Y. Acad. Sci. 851: 271-285, 1998.

Liu X., Zhang H., Wang J. et al:: Increased $\mathrm{CO}_{2}$ concentrations increasing water use efficiency and improvement PSII function of mulberry seedling leaves under drought stress. J. Plant Interact. 14: 213-223, 2019.

Manojlović M.S., Lončarić Z., Cabilovski R.R. et al.: Biofortification of wheat cultivars with selenium. - Acta Agr. Scand. B-S. P. 69: 715-724, 2019.

Marinaccio F., Reyneri A., Blandino M.: Enhancing grain yield and quality of winter barley through agronomic strategies to prolong canopy greenness. - Field Crop. Res. 170: 109-118, 2015.

Mevik B.-H., Wehrens R., Liland K.H.: pls: Partial least squares and principal component regression. R package version $2.7-0$, 2018. Available at: https://CRAN.R-project.org/package=pls (Accessed 20 July 2020)

Mlinarić S., Dunić J.A., Babojelić M.S. et al:: Differential accumulation of photosynthetic proteins regulates diurnal photochemical adjustments of PSII in common fig (Ficus carica L.) leaves. - J. Plant. Physiol. 209: 1-10, 2017.

Murata N., Takahashi S., Nishiyama Y., Allakhverdiev S.I.: Photoinhibition of photosystem II under environmental stress. - BBA-Bioenergetics 1767: 414-421, 2007.

Oukarroum A., El Madidi S., Schansker G., Strasser R.J.: Probing the responses of barley cultivars (Hordeum vulgare L.) by chlorophyll $a$ fluorescence OLKJIP under drought stress and re-watering. - Environ. Exp. Bot. 60: 438-446, 2007.

Oukarroum A., Schansker G., Strasser R.J.: Drought stress effects on photosystem I content and photosystem II thermotolerance analyzed using $\mathrm{Chl} a$ fluorescence kinetics in barley varieties differing in their drought tolerance. - Physiol. Plantarum 137: 188-199, 2009.

Panda D., Sarkar R.K.: Natural leaf senescence: probed by chlorophyll fluorescence, $\mathrm{CO}_{2}$ photosynthetic rate and antioxidant enzyme activities during grain filling in different rice cultivars. - Physiol. Mol. Biol. Pla. 19: 43-51, 2013.

Parrott D.L., McInnerney K., Feller U., Fischer A.M.: Steamgirdling of barley (Hordeum vulgare) leaves leads to carbohydrate accumulation and accelerated leaf senescence, facilitating transcriptomic analysis of senescence-associated genes. - New Phytol. 176: 56-69, 2007.

Parrott D.L., Yang L., Shama L., Fischer A.M.: Senescence is accelerated, and several proteases are induced by carbon "feast" conditions in barley (Hordeum vulgare L.) leaves. Planta 222: 989-1000, 2005.

Porter J.R., Semenov M.A.: Crop responses to climatic variation.Philos. T. Roy. Soc. B 360: 2021-2035, 2005.

Prasad P.V.V., Staggenborg S.A., Ristic Z.: Impacts of drought and/or heat stress on physiological, developmental, growth, and yield processes of crop plants. - In: Ahuja L.R., Reddy V.R., Saseendran S.A., Yu Q. (ed.): Response of Crops to Limited Water: Understanding and Modeling Water Stress Effects on Plant Growth Processes. Pp. 301-355. American Society of Agronomy, Crop Science Society of America, Soil Science Society of America, Madison 2008.

Rapacz M., Wójcik-Jagła M., Fiust A. et al.: Genome-wide 
associations of chlorophyll fluorescence OJIP transient parameters connected with soil drought response in barley. Front. Plant Sci. 10: 78, 2019.

Raun W.R., Solie J.B., Johnson G.V. et al.: In-season prediction of potential grain yield in winter wheat using canopy reflectance. - Agron. J. 93: 131-138, 2001.

Redillas M.C.F.R., Strasser R.J., Jeong J.S. et al.: The use of JIP test to evaluate drought-tolerance of transgenic rice overexpressing OsNAC10. - Plant. Biotechnol. Rep. 5: 169175, 2011.

Reynolds M.P., Langridge P.: Physiological breeding. - Curr. Opin. Plant Biol. 31: 162-171, 2016.

Reynolds M.P., Quilligan E., Aggarwal P.K. et al.: An integrated approach to maintaining cereal productivity under climate change. - Glob. Food Secur. 8: 9-18, 2016.

Strasser R.J., Srivastava A., Tsimilli-Michael M.: The fluorescence transient as a tool to characterize and screen photosynthetic samples. - In: Yunus M., Pathre U., Mohanty P. (ed.): Probing Photosynthesis: Mechanisms, Regulation and Adaptation. Pp. 445-483. Taylor \& Francis, London 2000.

Strasser R.J., Tsimilli-Michael M., Qiang S., Goltsev V.: Simultaneous in vivo recording of prompt and delayed fluorescence and 820-nm reflection changes during drying and after rehydration of the resurrection plant Haberlea rhodopensis. - BBA-Bioenergetics 1797: 1313-1326, 2010.

Strasser R.J., Tsimilli-Michael M., Srivastava A.: Analysis of the chlorophyll $a$ fluorescence transient. - In: Papageorgiou G.C., Govindjee (ed.): Chlorophyll $a$ Fluorescence: A Signature of Photosynthesis. Advances in Photosynthesis and Respiration. Pp. 321-362. Springer, Dordrecht 2004.

Strauss A.J., Krüger G.H.J., Strasser R.J., Van Heerden P.D.R.: Ranking of dark chilling tolerance in soybean genotypes probed by the chlorophyll $a$ fluorescence transient O-J-I-P. Environ. Exp. Bot. 56: 147-157, 2006.

Sun Z.W., Ren L.K., Fan J.W. et al.: Salt response of photosynthetic electron transport system in wheat cultivars with contrasting tolerance. - Plant Soil Environ. 62: 515-521, 2016.

Teulat B., Monneveux P., Wery J. et al.: Relationships between relative water content and growth parameters under water stress in barley: a QTL study. - New Phytol. 137: 99-107, 1997.

Thomas H., Ougham H.: The stay-green trait. - J. Exp. Bot. 65 : 3889-3900, 2014

Venkatesh J., Upadhyaya C.P., Yu J.-W. et al.: Chlorophyll a fluorescence transient analysis of transgenic potato overexpressing D-galacturonic acid reductase gene for salinity stress tolerance. - Hortic. Environ. Biote. 53: 320-328, 2012.

Viljevac Vuletić M., Španić V.: Characterization of photosynthetic performance during natural leaf senescence in winter wheat: Multivariate analysis as a tool for phenotypic characterization. - Photosynthetica 58: 301-313, 2020.

Vu V.Q.: ggbiplot: A ggplot2 based biplot. $R$ package version $0.55,2011$

Walsh O.S., Klatt A.R., Solie J.B. et al.: Use of soil moisture data for refined GreenSeeker sensor based nitrogen recommendations in winter wheat (Triticum aestivum L.). Precis. Agric. 14: 343-356, 2013.

Wold S., Esbensen K., Geladi P.: Principal component analysis. Chemomet. Intell. Lab. Syst. 2: 37-52, 1987.

Wu X., Tang Y., Li C. et al.: Chlorophyll fluorescence and yield responses of winter wheat to waterlogging at different growth stages. - Plant Prod. Sci. 18: 284-294, 2015.

Xu X.-G., Yang X.-D., Gu X.-H. et al.: Monitoring the ratio of leaf carbon to nitrogen in winter wheat with hyperspectral measurements. Proc. SPIE 9637, Remote Sensing for Agriculture, Ecosystems, and Hydrology XVII, 96371N, 2015. doi.org/10.1117/12.2194937

Xu X., Yang G., Yang X. et al.: Monitoring ratio of carbon to nitrogen $(\mathrm{C} / \mathrm{N})$ in wheat and barley leaves by using spectral slope features with branch-and-bound algorithm. - Sci. Rep.UK 8: 10034, 2018.

Yusuf M.A., Kumar D., Rajwanshi R. et al.: Overexpression of $\gamma$-tocopherol methyl transferase gene in transgenic Brassica juncea plants alleviates abiotic stress: physiological and chlorophyll $a$ fluorescence measurements. - BBABioenergetics 1797: 1428-1438, 2010.

Zhang M., Shan Y., Kochian L. et al.: Photochemical properties in flag leaves of a super-high-yielding hybrid rice and a traditional hybrid rice (Oryza sativa L.) probed by chlorophyll $a$ fluorescence transient. - Photosynth. Res. 126: 275284, 2015.

Zhang Z., Li G., Gao H. et al.: Characterization of photosynthetic performance during senescence in stay-green and quick-leafsenescence Zea mays L. inbred lines. - PLoS ONE 7: e42936, 2012.

Żurek G., Rybka K., Pogrzeba M. et al.: Chlorophyll a fluorescence in evaluation of the effect of heavy metal soil contamination on perennial grasses. - PLoS ONE 9: e91475, 2014.

Živčák M., Brestič M., Olšovská K., Slamka P.: Performance index as a sensitive indicator of water stress in Triticum aestivum L. - Plant Soil Environ. 54: 133-139, 2008.

(c) The authors. This is an open access article distributed under the terms of the Creative Commons BY-NC-ND Licence. 